\title{
Risk assessment of night-eating syndrome occurrence in women in Poland, considering the obesity factor in particular
}

This article was published in the following Dove Press journal:

Neuropsychiatric Disease and Treatment

\section{Dominik Olejniczak' \\ Dorota Bugajec ${ }^{2}$ \\ Anna Staniszewska ${ }^{3}$ \\ Mariusz Panczyk ${ }^{4}$ \\ Aleksandra Kielan' \\ Aleksandra Czerw' \\ Marta Mańczuk ${ }^{5}$ \\ Grzegorz Juszczyk' \\ Joanna Skonieczna' \\ Anna Brytek-Matera ${ }^{6}$ \\ 'Department of Public Health, Faculty of Health Science, Medical University of Warsaw, Warsaw, Poland; 'Students' Scientific Public Health Association, Health Promotion Section, Medical University of Warsaw, Warsaw, Poland; ${ }^{3}$ Department of Experimental and Clinical Pharmacology, Medical University of Warsaw, Warsaw, Poland; ${ }^{4}$ Division of Teaching and Outcomes of Education, Faculty of Health Science, Warsaw Medical University, Warsaw, Poland; ${ }^{5}$ Department of Cancer Epidemiology and Prevention, Maria Sklodowska-Curie Institute - Oncology Center, Warsaw, Poland; ${ }^{6}$ Katowice Faculty, SWPS University of Social Sciences and Humanities, Warsaw, Poland}

Correspondence: Dominik Olejniczak Warszawski Uniwersytet Medyczny, Zakład Zdrowia Publicznego,

Ul. Banacha Ia, blok F, p.30,

02-097 Warszawa, Poland

Tel +48 225992180

Fax +48 225992181

Email dominkolejniczak@op.pl
Introduction: Night-eating syndrome (NES) involves uncontrolled and most often repeated binge eating during the night. It is related with mood disorders as well as sleep disorders and it may cause obesity. Risks related to NES are obesity, binge eating disorder, bulimia nervosa, affective disorders, and sleep disorders. The objective of this study is to analyze eating habits in terms of the risk assessment of NES occurrence in the population of women in the Masovian Voivodeship (in Poland).

Patients and methods: Six hundred and eleven women living in the Masovian Voivodeship participated in the study. The average age of the respondents was 22.7 years (median $=23.0$; interquartile range $=3.0$ ). The Night Eating Questionnaire $(N E Q)$ was used to assess the risk of NES.

Results: In the studied group of women, $1.3 \%$ of cases $(\mathrm{N}=12)$ reached a NEQ total score of $\geq 25$, which indicates a probability of $40.7 \%$ for NES, while $0.7 \%(\mathrm{~N}=4)$ reached a score of $\geq 30$, which indicates a probability of $72.2 \%$ for occurrence of this syndrome. The highest average total score was observed in the group of obese people. The level of education of the participants did not significantly affect the NEQ score. A weak correlation was observed between the place of residence variable and the mood/sleep subscale $(r=0.11, P<0.01)$.

Conclusion: NES may be one of the causes of overweight and obesity; therefore, the need for further studies on this health issue is justified. It is worth pointing out that knowing the conditions responsible for the occurrence of NES, it is possible to suggest a prevention procedure for this condition.

Keywords: night-eating syndrome, women, obesity

\section{Introduction}

Night-eating syndrome (NES) was described for the first time in 1955 in the publication entitled "The night-eating syndrome: A pattern of food intake among certain obese patients" by Stunkard Grace and Wolff, who were studying obese patients. Their definition determined NES as a daily delayed pattern of food intake which was characterized by three symptoms: evening or night rage, insomnia, and morning anorexia. It was also stated that the symptoms intensify under stress and they can probably be mitigated by the reduction of stressful situations, if possible. Currently, the disorder defined as "night-eating syndrome" can be described as daily delayed food intake simultaneous with a normal daily rhythm of sleep. ${ }^{1,2}$

NES syndrome involves uncontrolled and most often repeated binge eating during the night. It is related with mood disorders and sleep disorders, and it may cause 
obesity. It may occur as an independent syndrome of symptoms or accompany other diseases, such as depression. ${ }^{3}$

NES has not been specified in the International Classification of Disease-10th revision classification as a separate disease. However, it has been considered in the classification of mental disorders of the American Psychiatric Association Diagnostic and Statistical Manual of Mental Disorders-5th edition in the category of "other specified feeding or eating disorder". 4,5

Since NES was first described, definitions used have been changing causing difficulties in the comparisons of studies. In April 2008, during the first international symposium concerning the NES, ${ }^{6}$ the team of gathered experts suggested a set of six diagnostic criteria (Table 1).

The largest risk associated with NES is the occurrence of accompanying disorders and their consequences: obesity, binge eating disorder (BED), bulimia nervosa, affective disorders, or sleep disorders. ${ }^{8}$ Apart from that, the disease may negatively affect attempts to lose weight and treat diabetes. Although the impact on losing weight is doubtful, as most reports concern small groups of participants and the disease being accompanied by other disorders, participants of slimming programs suffering from NES lost weight slower in comparison to participants in whom NES was not diagnosed. ${ }^{2,7}$

Prevalence of NES is estimated at $1.5 \%$ in the general population, ${ }^{9}$ while among obese people the prevalence is between $6 \%$ and $14 \%$, and from $8 \%$ up to $42 \%$ among people

\section{Table I First International NES Diagnostic Criteria}

I. Increased food intake in evening hours and/or at night manifested by:

a) consuming at least $25 \%$ of the total daily consumed food after dinner and/or

b) at least two episodes of night eating per week.

2. Being conscious during night-eating episodes and the possibility to remember them on the following day.

3. The clinical image is characterized by the occurrence of at least three of the five following features:

a) no desire to eat in the morning and/or skipping breakfast for four or more mornings per week

b) strong need to eat between dinner and falling asleep and/or at night

c) sleeplessness associated with the inability to sleep or maintain sleep at least four nights a week

d) believing that one needs to eat to initiate sleep or go back to sleep

e) depressive mood and/or worsening mood in the evening.

4. The syndrome must be related to significant discomfort and/or impaired functioning.

5. Symptoms must be maintained for at least 3 months.

6. The syndrome is not secondary in comparison to substance abuse or an addiction, a medical disorder, anxiety, or another mental disorder.

Note: Own elaboration based on data from Allison et $\mathrm{a}^{6}$ and Vander Wal. ${ }^{7}$

Abbreviation: NES, night-eating syndrome. qualified for the bariatric surgery in the USA. ${ }^{10}$ The wide range of estimates may result from various assessment methods (eg, examination vs interview) and diagnostic criteria. However, the results indicate that with an increase of fat tissue, the prevalence of NES also increases. NES was also described in $15 \%$ of people who came to be treated for BED. ${ }^{11}$

We have not completed studies showing the frequency of NES according to gender; however, the studies are more often conducted among women, which may affect the reliability of the results concerning the scale of prevalence. In a study conducted by Andersen et al, ${ }^{12}$ women and men confirmed waking up to eat in a similar proportion. The frequency of occurrence of the syndrome and its features among various racial groups is unknown. ${ }^{1,7}$

Finally, it is worth pointing out that a biobehavioral mechanism plays a relevant role in the NES. One study has shown ${ }^{13}$ that the serotonin transporter binding is elevated in the midbrain of individuals with NES, causing dysregulation of the circadian rhythm of both food intake and neuroendocrine function. The administration of selective serotonin reuptake inhibitors blocks the reuptake of serotonin and restores the circadian rhythm of both food intake and neuroendocrine function. ${ }^{13}$ The studies have demonstrated that NES occurs in genetically vulnerable people when exposed to stress, ${ }^{14}$ while depressive disorder, impulse control disorder, nicotine dependency, body dissatisfaction, and higher symptom severity are risk factors for the development of NES. ${ }^{15}$

\section{Patients and methods}

Six hundred and eleven women aged 19-30 years living in Poland participated in the study. The average age of the respondents was 22.7 years (median $=23.0$; interquartile range $=3.0$ ).

Nearly $30 \%$ of respondents $(79.1 \%)$ had their body mass index (BMI, calculated as the body mass in $\mathrm{kg}$ divided by height in $\mathrm{cm}$, squared $\left.{ }^{10}\right)$ in a normal range $\left(18.5-24.9 \mathrm{~kg} / \mathrm{cm}^{2}\right)$, $4.9 \%$ of women were underweight $\left(<18.5 \mathrm{~kg} / \mathrm{cm}^{2}\right), 11.1 \%$ were overweight $\left(25.0-29.9 \mathrm{~kg} / \mathrm{cm}^{2}\right)$, and $2.8 \%$ were obese $\left(\geq 30.0 \mathrm{~kg} / \mathrm{cm}^{2}\right)$. Most respondents (68.9\%) lived in Warsaw, $7.2 \%$ in a city with $100,000-500,000$ residents, $10.6 \%$ in a city with $10,000-100,000$ residents, $3.6 \%$ in a town below 10,000 residents, and $9.7 \%$ in a village. None of the respondents had primary education, and $0.3 \%$ of the respondents had vocational education, more than half $(55.5 \%)$ of the respondents had secondary education, and $44.2 \%$ had higher education. 
The objective of the study was to analyze eating habits in terms of the risk occurrence of NES in a population of women living in the Masovian Voivodeship in Poland.

The Night Eating Questionnaire (NEQ) developed by Allison et al was used to assess the risk of nigh-eating syndrome. ${ }^{16}$ It is a tool with confirmed psychometric properties in terms of internal consistency (Cronbach's alpha $=0.70$ ), fixed factor structure (four components), and convergent validity. NEQ consists of 14 questions scored at a five-grade Likert's scale (scoring from 0 to 4), except for question 7. Three questions are coded at a reverse scale and before counting the scope, they are subject to recoding. Results of the psychometric analysis indicate that NEQ consists of four subscales - nocturnal ingestions, evening hyperphagia, morning anorexia, and mood/sleep; however, the authors recommend using the aggregate score. The higher the score, the higher is the risk of NES. Results of the measurements obtained using NEQ were standardized. In the validation studies, a cutoff threshold for the aggregate scale score was established. The probability that NES will occur in people completing the questionnaire with a score $\geq 25$ was $40.7 \%$, while with a score of 30 points and more this probability increased to $72.2 \%$. Additionally, NEQ is completed with an additional question which allows the occurrence of insomnia and eating disorders associated with sleep to be excluded. Moreover, in people with a large risk of NES, additional questions concern the relation of the participant toward the symptoms and their duration. ${ }^{16}$

For preparing the Polish version of the NEQ, recommendations of the World Health Organization were used: "Process of translation and adaptation of instruments". ${ }^{17}$ The NEQ in the formula suggested by Allison et $\mathrm{al}^{16}$ was translated into Polish by two independent translators experienced in translating scientific texts in the field of psychology and psychiatrics. The review and comparison of translations indicated their high similarity in terms of the content of particular statements. The agreed Polish version was prepared by an expert panel consisting of a specialist in clinical psychology, a dietician, and a psychiatrist. The version of the NEQ prepared by the experts was assessed in a group of five students in terms of grammatical and stylistic correctness and understanding of the content of particular questions by recipients. The final version of the NEQ was not subject to back translation or tested in a group of bilingual respondents. The Polish scale was characterized by similar psychometric properties in terms of internal consistency (Cronbach's alpha $=0.65$ ) and a similar four-element factor structure. Validation studies of the Polish version of the NEQ have not been conducted.
The questionnaire was completed with additional questions concerning age, education, and place of residence. Moreover, the participants were asked to specify their current body mass and height. The data were used to calculate BMI. The computer-assisted web interviewing technique was used.

Consent of the Bioethics Committee of the Medical University of Warsaw was obtained for the research. Patients were informed about the objective of the study. Each patient qualified for the studies received information that the collected results will be used only for scientific purposes. Patients gave written consent to participate in the study.

\section{Statistical analysis}

The score obtained in the course of the study was calculated on the basis of the key described by Allison et al. ${ }^{16}$ Structural indicators describing the study group for non-occurrence/ occurrence of NES were determined. For the diagnosis purpose, two cutoff thresholds were used: $\geq 25$ and $\geq 30$ points. Apart from calculating the total score, results in terms of four subscales were also used. The impact of BMI on the total score and in particular the NEQ subscales was assessed using the linear regression method. Moreover, the obtained results were compared between two groups showing difference in education level (secondary vs higher education) and the place of residence (Warsaw vs village/city $<500$ thousand). For this purpose, Student's $t$-test was used to estimate the effect size using the $d$ coefficient calculated in accordance with the formula suggested by Cohen. ${ }^{18}$ According to the guidelines provided by Cohen, a large effect occurs in the case where the coefficient $d>0.80$, a medium effect in the case where $d=0.50-0.79$, and a small effect in the case where $d=0.20-0.49 .{ }^{19}$ All statistical analysis were performer using the statistical package Statistica 13.0 (Dell Inc., Tulsa, OK, USA). The a priori statistical significance level was set at 0.05 .

\section{Results}

In the studied group, we observed $1.3 \%$ of cases $(\mathrm{N}=12)$ with a total NEQ score of $\geq 25$ and $0.7 \%(\mathrm{~N}=4)$ with a total NEQ score of $\geq 30$. The highest average total score was observed in the group of obese people (BMI $\geq 30.0 \mathrm{~kg} / \mathrm{cm}^{2}$ ). In the same group, average results in all four subscales were also higher than in other groups. Average results in particular BMI categories showed the highest results in the group of obese and overweight people, while the lowest average results were observed in the group of people with normal BMI (Table 2). 
Table 2 Mean (SD) of the NEQ total score and subscales for all samples and BMI categories

\begin{tabular}{|c|c|c|c|c|c|}
\hline Variables & $\begin{array}{l}\text { NEQ } \\
\text { total }\end{array}$ & $\begin{array}{l}\text { Nocturnal } \\
\text { ingestion }\end{array}$ & $\begin{array}{l}\text { Evening } \\
\text { hyperphagia }\end{array}$ & $\begin{array}{l}\text { Morning } \\
\text { anorexia }\end{array}$ & Mood/sleep \\
\hline Sample $(\mathrm{N}=6 \mathrm{II})$ & $12.4(4.72)$ & $7.3(2.84)$ & $4.5(2.28)$ & $3.8(1.73)$ & $4.3(2.35)$ \\
\hline \multicolumn{6}{|l|}{ Category of BMI } \\
\hline Underweight $(N=30)$ & I $3.4(4.03)$ & $8.7(\mathrm{I} .53)$ & 4.7 (2.89) & $3.6(2.03)$ & $4.5(2.36)$ \\
\hline Normal $(\mathrm{N}=483)$ & I2.I (4.7I) & $6.9(3.08)$ & $4.4(2.25)$ & $3.8(1.74)$ & $4.3(2.39)$ \\
\hline Overweight ( $N=68)$ & $12.8(4.08)$ & $7.7(3.21)$ & $4.3(2.08)$ & $4.0(1.51)$ & $4.5(2.04)$ \\
\hline Obesity $(N=17)$ & $15.5(5.35)$ & $9.0(2.83)$ & $6.1(2.01)$ & $4.5(1.42)$ & $4.6(2.18)$ \\
\hline F-statistic & 3.145 & 0.555 & 3.091 & 1.784 & 0.323 \\
\hline$P$-value* & 0.033 & 0.650 & 0.027 & 0.162 & 0.809 \\
\hline
\end{tabular}

Note: *One-way ANOVA.

Abbreviations: NEQ, Night Eating Questionnaire; BMI, body mass index; ANOVA, analysis of variance.

The analysis of the BMI impact on the NEQ score indicates that it can be a significant factor for an increased risk of NES occurrence (Table 3). The total score of the participants was significantly dependent on the BMI value; however, the higher the index value, the higher were the results of the participants $\left(\beta_{\text {stand }}=0.09 ; P=0.022\right)$. A similar dependency however, with slightly larger strength - was observed in terms of the subscale of morning anorexia $\left(\beta_{\text {stand }}=0.11 ; P=0.007\right)$. The relationship observed between the BMI value and the NEQ score was modest.

The analysis of the impact of education of the participants did not indicate a significant correlation of this variable with the NEQ score, both in terms of total scope and in particular the NEQ subscales (Table 4). It was observed that residents of Warsaw reached significantly higher results in terms of total score and the mood/sleep subscale than people from outside the capital city. However, the observed effect size was small (Cohen's $d=0.15$ and 0.26 , respectively). Nonetheless, such a result may indicate greater exposure of the residents of a city to NES than the residents of suburban areas. It may result from the specificity of life in the city, faster pace of life, and,

Table 3 Results of the regression analysis assessing the BMI impact on the NEQ total score and subscales

\begin{tabular}{|c|c|c|c|c|c|c|}
\hline NEQ & Variable & $\beta_{\text {stand }}$ & $-95 \% \mathrm{Cl}$ & $+95 \% \mathrm{Cl}$ & t-statistic & $P$-value \\
\hline NEQ total & Intercept & & & & 8.46 & 0.000 \\
\hline score & BMI & 0.09 & 0.01 & 0.17 & 2.30 & 0.022 \\
\hline Nocturnal & Intercept & & & & 2.96 & 0.007 \\
\hline ingestion & BMI & 0.03 & -0.39 & 0.45 & 0.16 & NS \\
\hline Evening & Intercept & & & & 7.01 & 0.000 \\
\hline hyperphagia & $\mathrm{BMI}$ & 0.04 & -0.04 & 0.93 & 0.93 & NS \\
\hline Morning & Intercept & & & & 6.28 & 0.000 \\
\hline anorexia & $\mathrm{BMI}$ & 0.11 & 0.03 & 0.19 & 2.71 & 0.007 \\
\hline \multirow[t]{2}{*}{ Mood/sleep } & Intercept & & & & 6.23 & 0.000 \\
\hline & BMI & 0.05 & -0.03 & 0.13 & 1.20 & NS \\
\hline
\end{tabular}

Abbreviations: NEQ, Night Eating Questionnaire; BMI, body mass index; NS, not significant; $\beta_{\text {stand, }}$, standardized regression coefficient. therefore, increased exposure to stress, which is one of the NES determinants.

\section{Discussion}

NES constitutes a relatively new problem, which explains deficient empirical research concerning its course and insufficient knowledge about this phenomenon. Causes of NES are also not entirely clear.

In the authors' current study, it was indicated that among the 611 studied women there is a probability that $\sim 2 \%$ will have NES, while $0.7 \%(\mathrm{~N}=4)$ reached an NEQ total score of $\geq 30$, which indicates a probability of $72.2 \%$ for occurrence of this syndrome. This finding is consistent with that reported by Pinto et al and Rand et al, who estimated the prevalence of this condition to be $1.5 \%$ in the world. ${ }^{1,20}$ In a study by de Zwaan et al, conducted on the general population in Germany, prevalence of NES symptoms was indicated at $1.1 \% .{ }^{21}$ Similar results were obtained in the study conducted by Zadjali et al on the population of Oman where the criteria of NES were fulfilled by $1.5 \%$ of the studied people..$^{22}$ In the population consuming a Mediterranean diet, prevalence of NES was $3.5 \%$ with modified criteria, ie, consuming meals of small volumes or failing to eat breakfast, sleep disorders, and eating before sleep or during sleep. ${ }^{4}$

High values of the BMI index are positively correlated with the prevalence of NES. It is confirmed by the author's own study that the highest average total scope was observed in the case of obese people. ${ }^{9}$ However, NES also occurs in people with normal body mass. Marshall et al indicated that half of the obese people with coexisting NES report normal body mass before commencement of night-eating episodes. This suggests that NES can be one of the causes of overweight and obesity. ${ }^{23}$ The quadratic study by Allison et a ${ }^{24}$ conducted on a group of 845 patients demonstrated that the frequency of occurrence of NES among obese people with type 2 diabetes is $\sim 3.8 \%$, while in the study by Morse et al, ${ }^{25}$ 
Table 4 Mean (SD) of the NEQ total score and subscales in terms of education and the place of residence of the participants

\begin{tabular}{|c|c|c|c|c|c|}
\hline Variables & $\begin{array}{l}\text { NEQ } \\
\text { total }\end{array}$ & $\begin{array}{l}\text { Nocturnal } \\
\text { ingestion }\end{array}$ & $\begin{array}{l}\text { Evening } \\
\text { hyperphagia }\end{array}$ & $\begin{array}{l}\text { Morning } \\
\text { anorexia }\end{array}$ & Mood/sleep \\
\hline \multicolumn{6}{|l|}{ Education } \\
\hline Secondary $(N=339)$ & $12.6(4.58)$ & $7.3(2.4 I)$ & $4.6(2.32)$ & $3.9(1.77)$ & $4.4(2.33)$ \\
\hline Higher $(N=270)$ & I2.I (4.85) & $7.5(3.27)$ & $4.3(2.23)$ & $3.7(1.69)$ & $4.2(2.33)$ \\
\hline$t$-statistic & 1.143 & -0.166 & 1.284 & 1.349 & 0.811 \\
\hline$P$-value* & 0.254 & 0.870 & 0.199 & 0.178 & 0.418 \\
\hline \multicolumn{6}{|l|}{ Place of residence } \\
\hline Warsaw $(N=42 I)$ & $12.6(4.83)$ & $6.7(2.91)$ & $4.6(2.30)$ & $3.8(I .8 I)$ & $4.5(2.34)$ \\
\hline Village/city $<500,000(N=190)$ & II.9 (4.45) & $8.9(2.10)$ & $4.2(2.22)$ & $3.8(1.57)$ & $3.9(2.34)$ \\
\hline t-statistic & 1.749 & -1.921 & 1.693 & -0.042 & 2.774 \\
\hline$P$-value* & 0.081 & 0.066 & 0.091 & 0.967 & 0.006 \\
\hline
\end{tabular}

Note: *Student's t-test.

Abbreviation: NEQ, Night Eating Questionnaire.

in which 714 people participated, it was demonstrated that NES concerns $9.7 \%$ people suffering from diabetes. In the article by Kenardy et al, ${ }^{26}$ the occurrence of type 2 diabetes was confirmed with coexisting binge eating in young women. In addition, binge eating was related to low well-being, earlier age of diagnosis, low self-efficacy for diet, and exercise selfmanagement, as well as higher BMI. As authors suggest ${ }^{27}$ history of binge eating predicted age of diagnosis of diabetes, and binge eating could be considered an independent risk factor for type 2 diabetes.

In regard to our results, in world literature no study was found with the variable concerning the impact of education on NES. It should be studied in the future research.

The current investigation has been limited by a lack of measures for psychological (as perceived stress, quality of life) and psychopathological (as depressive disorder, impulse control disorder, nicotine dependency) variables.

It is worth highlighting that in the present study, it was observed that residents of Warsaw obtained statistically significantly higher results in terms of total scope and the mood/ sleep subscale. This indicates an increased risk of NES in this group. Assuming that populations living in agglomerations are exposed to a greater level of stress (due to the specificity of the place of residence or place of work), it can be stated that this result confirms the role of stress in the prevalence of NES, which is also referred to in the studies conducted by, among others, Allison et $\mathrm{al}^{27}$ and Gallant et al. ${ }^{28}$ This means that educational programs on how to deal with stress can help in NES prevention.

\section{Conclusion}

NES may be one of the causes of overweight and obesity; therefore, the need to conduct further studies on this health issue is justified. By knowing the conditions responsible for the occurrence of NES, it is possible to suggest the prevention procedure within this condition. NES has not been classified as a disease; therefore, further studies on this condition are required, which could lead to the establishment of precise diagnostic criteria.

\section{Disclosure}

The authors report no conflicts of interest in this work.

\section{References}

1. O'Reardon JP, Peshek A, Allison KC. Night eating syndrome: diagnosis, epidemiology and management. CNS Drugs. 2005;19(12): 997-1008.

2. Jaworski M, Krupińska P. Zespół jedzenia nocnego u dorosłych chorych na cukrzycę typu 2 [Night-eating syndrome in adults suffering from type 2 diabetes]. Diabetologia Kliniczna. Via Medica. 2012;1:17-24. Polish.

3. Bąk-Sosnowska M. Syndrom nocnego jedzenia [Night-eating syndrome]. Available from: http://www.psychiatria.pl/artykul/syndromnocnego-jedzenia/3363/2.html. Accessed April 24, 2017. Polish.

4. Jakuszkowiak K, Cubała WJ. Zespół jedzenia nocnego - rozpowszechnienie, diagnoza i leczenie [Night-eating syndrome-prevalence, diagnosis and treatment]. Via Medica. 2004;1(2):107-111. Polish.

5. The National Eating Disorders Association. Available from: https:// www.nationaleatingdisorders.org/other-specified-feeding-or-eatingdisorder. Accessed April 26, 2017.

6. Allison KC, Lundgren JD, O'Reardon JP, et al. Proposed diagnostic criteria for night eating syndrome. Int J Eat Disord. 2010;43(3): 241-247.

7. Vander Wal JS. Night eating syndrome: a critical review of the literature. Clin Psychol Rev. 2012;32(1):49-59.

8. Colles SL, Dixon JB, O'Brien PE. Night eating syndrome and nocturnal snacking: association with obesity, binge eating and psychological distress. Int J Obes. 2007;31(11):1722-1730.

9. Rand CSW, Macgregor MD, Stunkard AJ. The night eating syndrome in the general population and among post-operative obesity surgery patients. Int J Eat Disord. 1997;22:65-69.

10. de Zwaan M, Marschollek M, Allison KC. The night eating syndrome (NES) in bariatric surgery patients. Eur Eat Disord Rev. 2015;23(6): 426-434.

11. WHO. Physical status: the use and interpretation of anthropometry. Report of a World Health Organization (WHO) Expert Committee. Geneva, Switzerland: World Health Organization; 1995. 
12. Andersen GS, Stunkard AJ, Sorensen TIA, Pedersen L, Heitman BL. Night eating and weight change in middle-aged men and women. Int J of Obes. 2004;28(10):1138-1143.

13. Stunkard A, Lu XY. Rapid changes in night eating: considering mechanisms. Eat Weight Disord. 2010;15(1-2):2-8.

14. Stunkard AJ, Allison KC, Lundgren JD, O'Reardon JP. A biobehavioural model of the night eating syndrome. Obes Rev. 2009; 10(Suppl 2):69-77.

15. Saraçlı Ö, Atasoy N, Akdemir A, et al. The prevalence and clinical features of the night eating syndrome in psychiatric out-patient population. Compr Psychiatry. 2015;57:79-84.

16. Allison KC, Lundgren JD, O'Reardon JP. The Night Eating Questionnaire (NEQ): psychometric properties of a measure of severity of the night eating syndrome. Eating Behaviors. 2008;9(1):62-72.

17. World Health Organization. Management of substance abuse. Available from: http://www.who.int/substance_abuse/research_tools/translation/en/. Accessed April 26, 2017.

18. Cohen J. Statistical Power Analysis for the Behavioral Sciences. 2nd ed. Hillsdale, NJ: Erlbaum; 1988.

19. Coolican H. Research Methods and Statistics in Psychology. London: Hodder; 2009.

20. Pinto TF, Coutinho da Silva FG, Sales de Bruin VM, Carvalhedo de Bruin PF. Night eating syndrome: how to treat it? Rev Assoc Med Bras. 2016;62(7):701-770.
21. de Zwaan M, Müller A, Allison KC, Brähler E, Hilbert A. Prevalence and correlates of night eating in the German general population. PLoS One. 2014;9(5):e97667.

22. Zadjali F, Al-Bulushi A, AlHassani F, Al Hinai M. Proportion of night eating syndrome in Arab population of Oman. $J$ Eat Disord. 2015;3:43.

23. Marshall HM, Allison KC, O'Reardon JP, Birketvedt G, Stunkard AJ. Night eating syndrome among nonobese persons. Int $J$ Eat Disord. 2004;35(2):217-222.

24. Allison KC, Crow JS, Reeves RR, et al. Binge eating disorder and night eating syndrome in adults with type 2. Diabetes Obes. 2007;15: 1287-1293.

25. Morse SA, Ciechanowski PS, Katon JK, Hirsch IB. Isn't this just bedtime snacking? The potential adverse effects of night-eating symptoms on treatment adherence and outcomes in patients with diabetes. Diabetes Care. 2006;29(8):1800-1804.

26. Kenardy J, Mensch M, Bowen K, et al. Disordered eating behaviors in women with type 2 diabetes mellitus. Eating Behav. 2001;2(2): 183-192.

27. Allison $\mathrm{KC}$, Tarves EP. Treatment of night eating syndrome. Psychiatr Clin North Am. 2011;34(4):785-796.

28. Gallant AR, Lundgren JD, Drapeau V. The night-eating syndrome and obesity. Obesity Rev. 2012;13(6):528-536.
Neuropsychiatric Disease and Treatment

\section{Publish your work in this journal}

Neuropsychiatric Disease and Treatment is an international, peerreviewed journal of clinical therapeutics and pharmacology focusing on concise rapid reporting of clinical or pre-clinical studies on a range of neuropsychiatric and neurological disorders. This journal is indexed on PubMed Central, the 'PsycINFO' database and CAS,

\section{Dovepress}

and is the official journal of The International Neuropsychiatric Association (INA). The manuscript management system is completely online and includes a very quick and fair peer-review system, which is all easy to use. Visit http://www.dovepress.com/testimonials.php to read real quotes from published authors. 